\title{
Komparasi Metode Analitical Hierarchy Procces Dan Simple Additive Weigthing Dalam Pemilihan Kinerja Guru
}

\author{
Lestari Yusuf ${ }^{1}$, Rahmawati $^{2}$, Dewi Ayu Nur Wulandari ${ }^{3}$ \\ ${ }^{1,2}$ Sekolah Tinggi Manajemen Informatika dan Komputer Nusa Mandiri \\ e-mail: lestariyusuf@gmail.com,rachma083@gmail.com
}

${ }^{3}$ Fakultas Teknologi Infomasi, Universitas Bina Sarana informatika e-mail: Dewi.dan@bsi.ac.id

\begin{tabular}{ccc}
\hline Diterima & Direvisi & Disetujui \\
$15-12-2019$ & $16-12-2019$ & $17-12-2019$ \\
\hline
\end{tabular}

\begin{abstract}
Abstrak - Guru yang memenuhi kinerja sesuai ketentuan setiap sekolah dapat ditentukan menggunakan sistem pengambilan keputusan. Dengan memiliki kinerja guru yang baik SMK Muhammadiyah 15 Jakarta dapat meningkatkan mutu sekolahnya juga dapat dijadikan syarat sebagai promosi jabatan setiap guru kejenjang berikutnya. Kriteria yang banyak tetapi tidak digunakan sepenuhnya dan masih menggunakan pilihan yang seadanya menyebabkan penilaian kriteria guru tidak objektif. Sistem pengambilan keputusan akan membantu menentukan penilaian kriteria terbaik untuk guru SMK Muhammadiyah 15 Jakarta. Dengan banyaknya metode sistem pengambilan keputusan, maka perlu dibuat sebuah perbandingan metode sistem pengambilan keputusan, agar pembaca mengetahui, metode mana yang lebih akurat digunakan untuk pengambilan keputusan kinerja guru terbaik. Dengan menggunakan lima kriteria penilaian kinerja guru yaitu tanggung jawab, disiplin, absensi, kualitas kerja dan kerjasama, dalam penelitian ini akan membandingkan dua metode sistem pengambilan keputusan antara AHP dan SAW. Hasil yang akan didapat adalah ranking guru dengan kinerja terbaik dan mengetahui metode mana yang lebih baik digunakan dan akurat dalam penentuan ranking kinerja guru terbaik di SMK Muhammadiyah 15 Jakarta.
\end{abstract}

Kata Kunci: Komparasi metode, sistem pengambilan keputusan, kinerja guru.

Abstract - Teachers who meet performance according to the provisions of each school can be determined using a decision making system. By having a good teacher's performance at SMK Muhammadiyah 15 Jakarta, it can improve the quality of the school and can also be used as a promotion for the position of each subsequent level teacher. The criteria are many but not fully used and still use improper choices causing the assessment of teacher criteria is not objective. The decision support system will help determine the best assessment criteria for teachers of SMK Muhammadiyah 15 Jakarta. With so many decision-support system methods, it is necessary to make a comparison of decision-support system methods, so that the reader knows, which method is more accurate used for the decision making of the best teacher performance. By using the five criteria for evaluating teacher performance, namely responsibility, discipline, presence, quality of work and collaboration, this research will compare the two methods of decision making systems between AHP and SAW. The results will be obtained is the ranking of the teachers with the best performance and know which method is better used and accurate in determining the ranking of the best teacher performance at SMK Muhammadiyah 15 Jakarta.

Keywords: Comparing methode, Desicion Support System, Teachers performan.

\section{PENDAHULUAN}

Pendidik profesional yang memiliki tugas utama, mendidik, membimbing, mengarahkan, menilai, melatih dan mengevaluasi peserta didik disebut dengan guru (UU no 14 tahun 2005). Penilaian Kinerja Guru yang menjamin terjadinya proses pembelajaran yang berkualitas disemua jenjang pendidikan diperlukan agar fungsi dan tugas yang melekat pada jabatan fungsional guru dapat dilaksanakan sesuai dengan aturan (Paramita, Mustika, \& Farkhatin, 2017).

Beberapa aspek kinerja seperti disiplin dalam KBM, loyal dan berdedikasi harus dimiliki oleh setiap guru agar dapat dipromosikan ke jenjang berikutnya merupakan upaya peningkatan mutu di SMK Muhammadiyah 15 Jakarta. Untuk mendukung upaya peningkatan mutu SMK tersebut maka menjadi alasan pentingnya menentukan guru yang aktif dan berprestasi di sekolah. Dan 
peningkatan mutu tersebut didapat dari penilaian kinerja guru.

Proses penilaian kinerja guru seringkali dinilai dari segi golongan dan tingkat pendidikan. Maka diperlukannya sistem pengambil keputusan (Satria \& Mutiah, 2014). Salah satu upaya yang dilakukan untuk memenuhi tuntutan sumber daya manusia yang bermutu tinggi dan siap berkompetisi baik pada tataran nasional, regional maupun internasional adalah dengan cara melakukan pemilihan guru berprestasi (Rahayu, 2017).

Proses yang terjadi selama ini untuk $\begin{array}{llll}\text { pemilihan kinerja guru di SMK } 15 & \text { SM }\end{array}$ Muhamammadiyah jakarta dilakukan oleh kepala sekolah, pihak sekolah hanya menggunakan dua kriteria dalam pemilihan, maka sering terjadi penilaian yang tidak objektif. Penetapan kinerja guru yang sudah memenuhi kualitas yang diterima oleh pihak sekolah atau tidak yang didasari oleh beberapa kriteria, semua ini dapat dibantu menggunakan sistem pengambilan keputusan agar pemilihan kinerja guru berjalan secara objektif dengan kriterikriteria yang sudah ditentukan sebelumnya. Proses yang masih dilakukan secara manual oleh pengambil keputusan yaitu kepala sekolah yang menimbulkan peluang terjadinya kesalahan dan memakan banyak waktu juga tenaga dan menjadi tidak efektif dan efisien (Putra, Aryanti, \& Hartati, 2018).

Banyak metode yang dapat digunakan untuk membantu menentukan keputusan dalam pemilihan kinerja guru. Seperti diantaranya yang pernah dilakukan oleh (Paramita et al., 2017), juga ada yang menggunakan metode Topsis (Duwiyanti, Fitri; Ardhiansyah, 2019) dan juga metode yang pernah digunakan untuk penyelesaian masalah ini adalah SAW (Simple Additive Weigthing) seperti yang pernah dibuat oleh (Chintyari \& Priharin, 2015) dan juga.

100 sample jurnal penelitian yang diambil baik dari internet maupun studi pustaka tentang penilaian kinerja yang berhubungan dengan pengimplementasian terhadap penilaian kinerja, SAW (Simple Additive Weighting) dan AHP (Analythical Hierarchy Process) merupakan metode yang paling mendominasi diantara metode yang lainnya (Shiddieq \& Septyan, 2017).

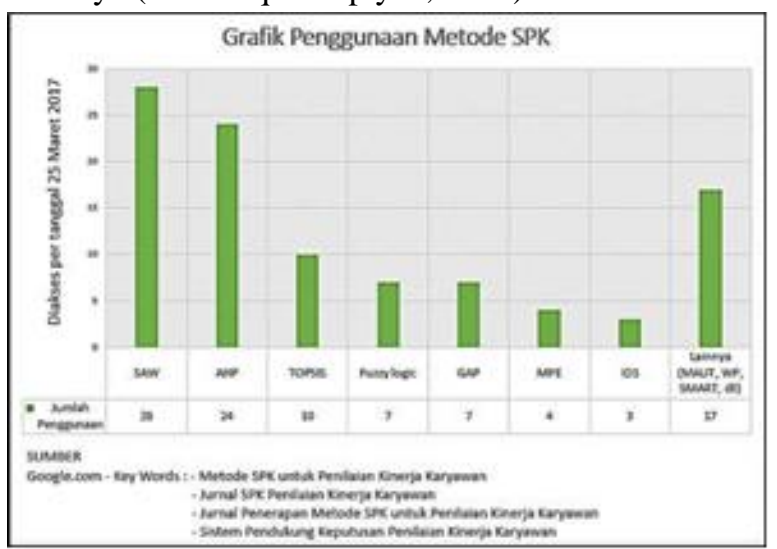

Sumber: (Shieddiq, Diqy Fakhrun; Septyan , Ervan, 2017).

Gambar 1. Grafik penggunaan metode SPK

Pada penelitian kali ini sistem keputusan yang diambil akan dibandingkan dengan sistem keputusan lainnya, metode yang akan dibandingkan adalah AHP (Analythic Hierarchy Process) dengan SAW(Simple Additive Weigthing). Membandingkan metode SAW dan AHP pun sebelumnya pernah dilakukan oleh (Pradipta \& Diana, 2017). Maka dalam penelitian ini, akan membandingkan dua metode sistem pengambilan keputusan AHP dan SAW yang menggunakan lima kriteria penilaian kinerja guru yaitu tanggung jawab, disiplin, absensi, kualitas kerja dan kerjasama untuk mendapatkan tujuan metode mana yang lebih baik untuk menentukan kinerja guru terbaik, mencari metode mana yang lebih dipahami juga metode mana yang lebih akurat digunakan untuk menentukan kinerja guru terbaik.

\section{METODOLOGI PENELITIAN}

Metode penelitian pada penulisan ini digambarkan oleh bagan dibawah ini:

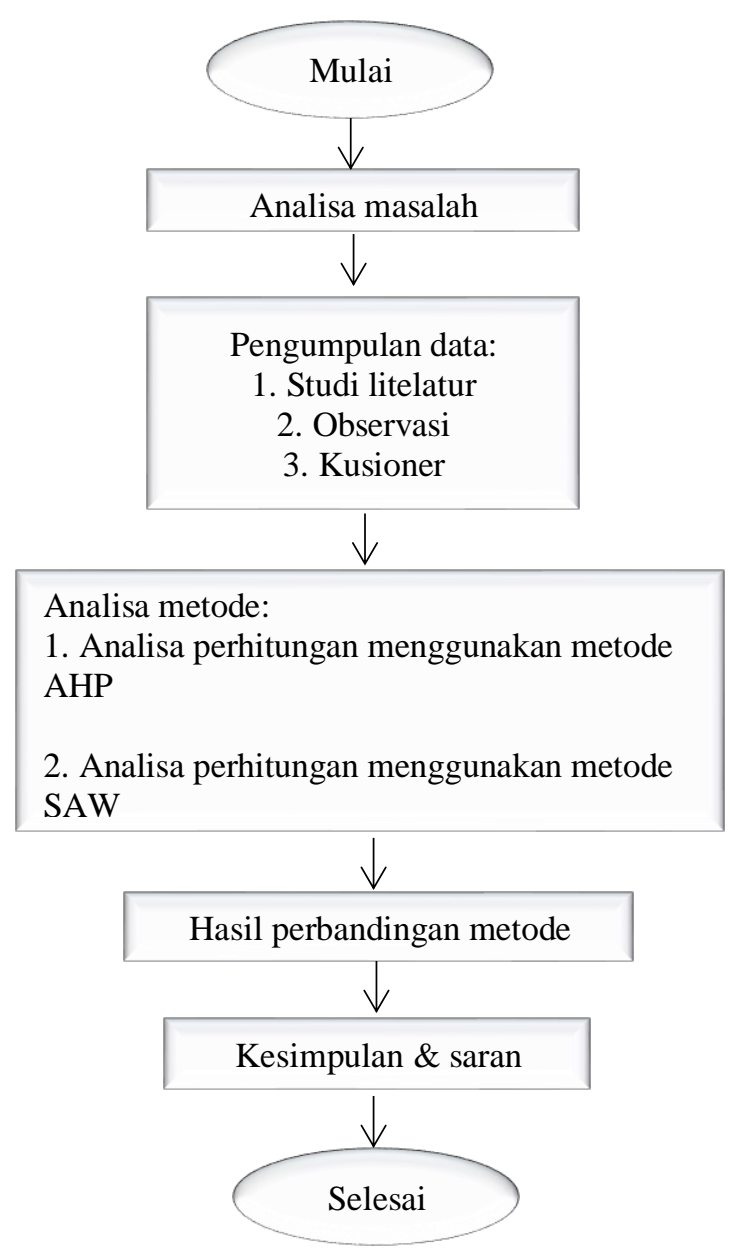

Sumber : (Penelitian, 2019)

Gambar 2. Metodelogi Penelitian 


\section{HASIL DAN PEMBAHASAN}

Tahap pertama yang akan dilakukan pada pembahasan ini adalah dekomposisi.

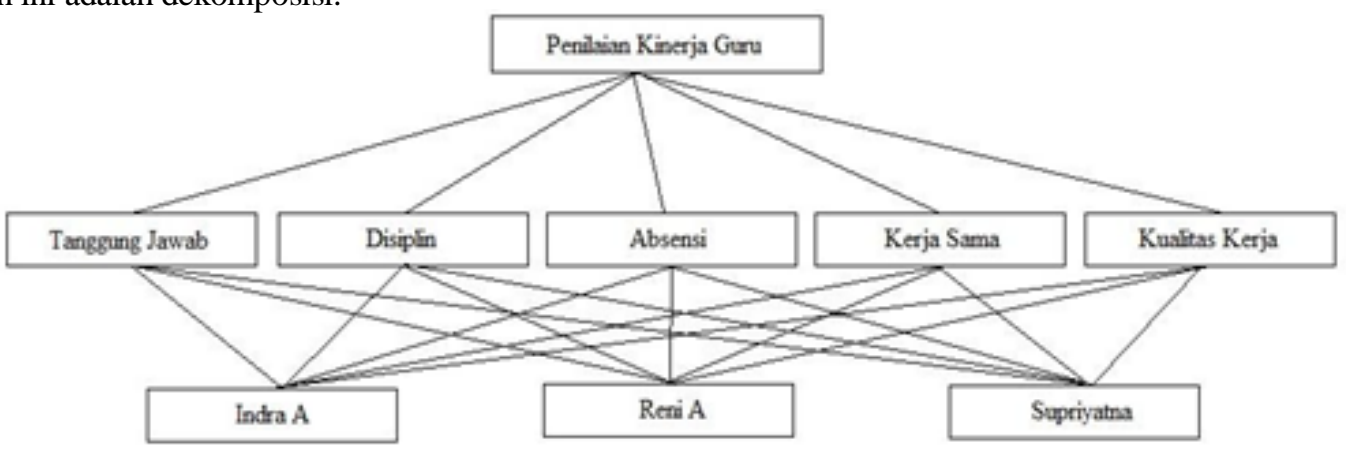

Sumber: (Penelitian, 2019)

\section{Gambar 3. Kriteria penilaian kinerja guru}

Tahap pertama yang akan dilakukan adalah menyelesaikan tahap metode AHP terlebih dahulu yang terdiri dari pencarian bobot berdasarkan perbandingan kriteria, menentukan vektor eigen, perhitungan konsistensi index dan rasio lalu terakhir adalah menentukan eigen vektor keputusan. Sementara untuk tahapan metode SAW setelah pencarian bobot dilakukan menggunakan cara perhitungan AHP maka perhitungan dilanjutkan dengan menentukan rating kecocokan setiap alternatif pada setiap kriteria, menentukan matriks keputusan berdasarkan kriteria, melakukan normalisasi matriks, menentukan pembobotan alternatif, lalu langkah yang terakhir adalah perangkingan.

\section{Analisa dan penerapan metode AHP}

Metode AHP menggunakan data populasi yang disebut data responden atau data sample, oleh karena itu teknik responden ini tidak dilakukan secara acak, melainkan ditentukan berdasarkan pertimbangan atau sampling purposive (Fauzi \& Hidayatulloh, 2017).

\section{a. Melakukan Perbandingan Berpasangan}

Langkah pertama dalam metode ini adalah melakukan perbandingan berpasangan antar kriteria dan memasukannya kedalam matrik. Dalam penelitian ini terdapat 6 responden yang melakukan pengisian perbandingan nilai. Data kuesioner yang telah diisi dan dikumpulkan, dirangkum ke dalam bentuk tabel perbandingan berpasangan yaitu:

1. Tabel perbandingan berpasangan antar elemen level 1 berdasarkan kriteria utama.

2. Tabel perbandingan berpasangan antar elemen level 2 berdasarkan kriteria tanggung jawab.
3. Tabel perbandingan berpasangan antar elemen level 2 berdasarkan kriteria disiplin.

4. Tabel perbandingan berpasangan antar elemen level 2 berdasarkan kriteria absensi.

5. Tabel perbandingan berpasangan antar elemen level 2 berdasarkan kriteria kerja sama.

6. Tabel perbandingan berpasangan antar elemen level 2 berdasarkan kriteria kualitas kerja

Maka langkah selanjutnya adalah mencari rata-rata perbandingan untuk masing-masing elemen dengan cara mengalikan semua elemen matriks perbandingan yang seletak kemudian diakar pangkatkan dengan banyaknaya responden. Maka didapatkan tabel perhitungan rata-rata untuk masingmasing elemen sebagai berikut:

\section{Table 1. Perbandingan rata-rata kriteria utama}

\begin{tabular}{lllllr}
\hline Kriteria & $\begin{array}{l}\text { Tanggung } \\
\text { Jawab }\end{array}$ & $\begin{array}{l}\text { Disi } \\
\text { plin }\end{array}$ & $\begin{array}{l}\text { Abse } \\
\text { nsi }\end{array}$ & $\begin{array}{r}\text { Kerja } \\
\text { Sama }\end{array}$ & $\begin{array}{r}\text { Kualitas } \\
\text { Kerja }\end{array}$ \\
\hline $\begin{array}{l}\text { Tanggung } \\
\text { Jawab }\end{array}$ & 1 & 3,0000 & 5,1369 & 5,4332 & 5,9925 \\
\hline Disiplin & 0,3333 & 1 & 4,8568 & 4,5180 & 4,2172 \\
\hline Absensi & 0,1947 & 0,2059 & 1 & 5,9161 & 5,2884 \\
\hline $\begin{array}{l}\text { Kerja } \\
\text { Sama }\end{array}$ & 0,1841 & 0,2213 & 0,1690 & 1 & \\
\hline $\begin{array}{l}\text { Kualitas } \\
\text { Kerja }\end{array}$ & 0,1669 & 0,2371 & 0,1891 & 0,2811 & \\
\hline Total & 1,8789 & 4,6644 & 11,3519 & 17,1485 & 20,0549 \\
\hline
\end{tabular}

Sumber: (Penelitian 2019)

Lalukan langkah yang sama untuk semua alternatif.

b. Menentukan Vector Eigen 
Setelah menemukan matriks berpasangan, langkah selanjutnya adalah menentukan vector eigen dari setiap matriks perbandingan berpasangan dengan langkah-langkah berikut:

1. Menjumlahkan nilai-nilai dari setiap kolom pada matriks.

2. Membagi setiap nilai dari kolom dengan total kolom yang bersangkutan untuk memperoleh normalisasi matriks.

3. Menjumlah nilai dari setiap baris dan membagi dengan jumlah elemen untuk mendapatkan nilai rata-rata.

Tabel 2. Vector Eigen Kriteria Utama

\begin{tabular}{ccccccc}
\hline Kriteria & $\begin{array}{c}\text { Tanggung } \\
\text { Jawab }\end{array}$ & $\begin{array}{c}\text { Disipli } \\
\text { n }\end{array}$ & $\begin{array}{c}\text { Absen } \\
\text { si }\end{array}$ & $\begin{array}{c}\text { Kerja } \\
\text { Sama }\end{array}$ & $\begin{array}{c}\text { Kualitas } \\
\text { Kerja }\end{array}$ & $\begin{array}{c}\text { Eigen } \\
\text { Vektor }\end{array}$ \\
\hline $\begin{array}{c}\text { Tanggun } \\
\text { g }\end{array}$ & & & & & & \\
Jawab & 1 & 3,0000 & 5,1369 & 5,4332 & 5,9925 & 0,5571 \\
\hline Disiplin & 0,3333 & 1 & 4,8568 & 4,5180 & 4,2172 & 0,2328 \\
\hline Absensi & 0,1947 & 0,2059 & 1 & 5,9161 & 5,2884 & 0,1125 \\
\hline $\begin{array}{c}\text { Kerja } \\
\text { Sama }\end{array}$ & 0,1841 & 0,2213 & 0,1690 & 1 & 3,5569 & 0,0558 \\
\hline $\begin{array}{c}\text { Kualitas } \\
\text { Kerja }\end{array}$ & 0,1669 & 0,2371 & 0,1891 & 0,2811 & 1 & 0,0417 \\
\hline & & & & & & \\
\hline
\end{tabular}

Jumlah

1,0000

Sumber: (Penelitian, 2019)

Perhitungan untuk setiap alternatif pun dilakukan dengan langkah yang sama.

\section{c. Consystency}

Tahap consistency ini bertujuan untuk menentukan kebenaran nilai eigen vektor yang diperoleh dari proses synthesis of priority yang telah dibuat sebelumnya. Pada penelitian ini, tahap consistency dilakukan sebanyak 6 kali, diantaranya sebagai berikut :

Hal pertama yang dilakukan pada tahap konsistensi (consistency) adalah menentukan lamda maksimum, matriks perbandingan berpasangan dikalikan dengan eigen vektor. Matriks perbandingan berpasangan yang digunakan adalah yang belum dinormalisasi. perbandingan berpasangann dengan vektor eigen normalisasi.

$\begin{array}{llllllll}1,0000 & 3,0000 & 5,1369 & 5,4332 & 5,9925 & 0,5771 & 1,0468 \\ 0,3333 & 1,0000 & 4,8568 & 4,5180 & 4,2172 & 0,2328 & 1,0860 \\ & & & & & \mathbf{X} & & \\ 0,1947 & 0,2059 & 1,0000 & 5,9161 & 5,2884 & 0,1125= & 1,2775 \\ 0,1841 & 0,2213 & 0,1690 & 1,0000 & 3,5569 & 0,0558 & 0,9570 \\ 0,1669 & 0,2371 & 0,1891 & 0,2811 & 1,0000 & 0,0417 & 0,8366\end{array}$

Hasil dari perkalian sebelumnya dijumlahkan sehingga menghasilkan lamda maksimal yaitu 5,2039 .

Tahap kedua dari proses konsistensi adalah menguji konsistensi hirarki, sebagai berikut :

Menghitung indeks konsistensi (Consistency Index = CI) dengan rumus :

$$
\mathrm{CI}=((\lambda \text { maksimum }-\mathrm{n}) /(\mathrm{n}-1)
$$

Keterangan :

$\mathrm{n}=$ banyaknya baris dan kolom matriks perbandingan berpasangan atau banyaknya kriteria.

Karena matriks berordo 5 atau terdiri dari 5 kriteria utama, maka nilai indeks konsistensi (CI) yang diperoleh adalah:

$$
\mathrm{CI}=\frac{\lambda \text { maks }-\mathrm{n}}{(\mathrm{n}-1)}=\frac{5,2039-5}{(5-1)}=0,0510
$$

Menghitung rasio konsistensi (Consistency Ratio = CR) dengan rumus :

\section{$\mathrm{CR}=\mathrm{CI} / \mathrm{RI}$}

Keterangan : RI adalah nilai-nilai acak yang diperoleh dari tabel Random Consistency Index pada n tertentu.

Tabel 2. Nilai IR (Indeks Random)

\begin{tabular}{|c|c|}
\hline $\begin{array}{l}\text { Ukuran } \\
\text { Matriks } \\
(\mathbf{n})\end{array}$ & $\begin{array}{c}\text { Nilai IR (Indeks } \\
\text { Random) }\end{array}$ \\
\hline 1,2 & 0.00 \\
\hline 3 & 0.58 \\
\hline 4 & 0.90 \\
\hline 5 & 1.12 \\
\hline 6 & 1.24 \\
\hline 7 & 1.32 \\
\hline 8 & 1.41 \\
\hline 9 & 1.45 \\
\hline
\end{tabular}

Sumber: (Penelitian, 2019) 


$$
\begin{aligned}
\mathrm{CR} & =\mathrm{CI} / \mathrm{RI} \\
& =0,0510 / 1,12 \\
& =0,0455
\end{aligned}
$$

Karena CR $<0.1 \quad(10 \%)$ maka preferensi pembobotan adalah konsisten.

Matriks perbandingan berpasangan level 1 berdasarkan kriteria utama telah diisi dengan pertimbangan-pertimbangan yang konsisten dan eigen vector yang dihasilkan dapat diandalkan.

\section{d. Menentukan Eigen Vektor Keputusan}

Tabel 3. Eigen Vektor Keputusan

\begin{tabular}{lrlllll}
\hline \multicolumn{1}{c}{$\begin{array}{c}\text { Tanggun } \\
\text { Jawab }\end{array}$} & Disiplin Absensi & $\begin{array}{l}\text { Kerja } \\
\text { Sama }\end{array}$ & $\begin{array}{l}\text { Kualitas } \\
\text { Kerja }\end{array}$ & \multicolumn{2}{c}{$\begin{array}{l}\text { EV } \\
\text { Keputusan }\end{array}$} \\
\hline Indra A & 0,7002 & 0,7414 & 0,7442 & 0,7036 & 0,7688 & 0,7317 \\
\hline Reni A & 0,2430 & 0,1932 & 0,1966 & 0,2381 & 0,1738 & 0,2279 \\
\hline Supriyatna & 0,0568 & 0,0654 & 0,0592 & 0,0583 & 0,0594 & 0,0604 \\
\hline
\end{tabular}

Sumber: (Penelitian, 2019)

Hasil operasi perkalian tersebut disebut sebagai eigen vektor keputusan, keputusan ditentukan oleh nilai yang mempunyai jumlah paling besar.

Dari eigen vektor keputusan terlihat bahwa :

1. Indra A memiliki bobot prioritas tertinggi yaitu 0,7317

2. Reni A memiliki bobot prioritas kedua yaitu 0,2279

3. Supriyatna memiliki bobot prioritas terendah yaitu 0,0604

\section{Analisa dan penerapan menggunakan metode SAW}

Pehitungan algoritma Simple Additive Weitghing diawalai dengan proses menentukan kriteria pada suatu alternatif, kemudian melakukan konversi yang didasarkan pada alternatif dan kriteria yang sida terdata, yang kemudian menghasilkan nilai normalisasi yang akan di ajdikan perkalian matriks untuk mendapatkan peramkingan (Sunarti \& Sundari, 2018). Perhitungan metode dengan cara pencarian bobot kriteria lalu mencari bobot alternatif dengan pola perhitungan yang berbeda dengan AHP. Mencari rating kinerja ternormalisasi yang jika nilainya semakin besar semakin baik dihitung dengan formula Benefit, sedangkan alternatif yang jika nilainya semakin kecil maka semakin baik dihitung dengan formula Cost. Berikut formula untuk mencari alternatif tersebut:

$r_{i j}=\left\{\begin{array}{l}\frac{x_{i j}}{\operatorname{Max} x_{i j}} \text { Jika } j \text { adalah atribut keuntungan (benefit) } \\ \frac{\text { Min } x_{i j}}{x_{i j}} \text { Jika } j \text { adalah atribut biaya }(\text { cost })\end{array}\right.$

Keterangan:

$\mathrm{r}_{\mathrm{ij}} \quad$ : rating kinerja ternormalisasi

$\max x_{i j}$ : Nilai maksimum dari setiap baris dan kolom

$\min \mathrm{x}_{\mathrm{ij}} \quad$ : Nilai minimum dari setiap baris dan kolom

$\mathrm{X}_{\mathrm{ij}} \quad$ : Baris dan kolom matriks

a. Pencarian bobot alternatif

Tabel 6. Pembobotan alternatif

\begin{tabular}{lrrrrr} 
& C1 & C2 & C3 & C4 & C5 \\
\hline A1 (Indra) & 5 & 9 & 1 & 7 & 7 \\
\hline A2(Reni) & 5 & 5 & 6 & 3 & 5 \\
\hline A3(Supriyatna) & 3 & 3 & 2 & 9 & 7 \\
\hline
\end{tabular}

Sumber: (Penelitian, 2019)

Pencarian pembobotan diisi oleh pemberi keputusan.

\section{b. Normalisasi Matriks Keputusan}

Nilai normalisasi matriks merupakan konversi dari nilai bobot ke dalam bilangan crips. Dimana bilangan crips ditentukan menggunakan teori penalaran yang jika bilangan mendekati angka 0 maka tingkat ketergantungan semakin rendah, sebaliknya jika bilangan mendekati angka 1 maka tingkat ketergantungan semakin tinggi (Suhada, Hidayatulloh, \& Fatimah, 2018).

$x=\left[\begin{array}{rclrr}0,625 & 1 & 0,875 & 0,875 & 0,875 \\ 0,625 & 0,625 & 0,25 & 0,375 & 0,625 \\ 0,375 & 0,375 & 0,75 & 1 & 0,875\end{array}\right]$

\section{c. Perhitungan Alternatif}

\section{Perhitungan alternatif 1}

$r_{11=\frac{0,625}{\max \{0,625 ; 0,625 ; 0,375\}}}=1,000$

$r_{12}=\frac{0,625}{\max \{0,625 ; 0,625 ; 0,375\}}=1,000$

$r_{13}=\frac{0,375}{\max \{0,625 ; 0,625 ; 0,375\}}=0,6$ 


\section{Perhitungan alternatif 2}

$$
\begin{aligned}
& r_{21=} \frac{1}{\max \{1 ; 0,625 ; 0,375\}}=1 \\
& r_{22=\frac{0,625}{\max \{1 ; 0,625 ; 0,375\}}=0,625} \\
& r_{21=\frac{0,375}{\max \{1 ; 0,625 ; 0,375\}}}=0,375
\end{aligned}
$$

\section{Perhitungan alternatif 3}

$$
\begin{aligned}
& r_{31}=\frac{\min \{0,875 ; 0,25 ; 0,75\}}{0.875}=0,286 \\
& r_{32}=\frac{\min \{0,875 ; 0,25 ; 0,75\}}{0.25}=1 \\
& r_{33}=\frac{\min \{0,875 ; 0,25 ; 0,75\}}{0.75}=0,333
\end{aligned}
$$

\section{Perhitungan alternatif 4}

$$
\begin{aligned}
& r_{41}=\frac{0,875}{\max \{0,875 ; 0,375 ; 1\}}=0,875 \\
& r_{42}=\frac{0,375}{\max \{0,875 ; 0,375 ; 1\}}=0,375 \\
& r_{43}=\frac{1}{\max \{0,875 ; 0,375 ; 1\}}=1
\end{aligned}
$$

\section{Perhitungan alternatif 5}

$$
\begin{aligned}
& r_{51=\frac{0,875}{\max \{0,875 ; 0,625 ; 0,875\}}}=1 \\
& r_{51=\frac{0,625}{\max \{0,875 ; 0,625 ; 0,875\}}}=0,714 \\
& r_{51=\frac{0,875}{\max \{0,875 ; 0,625 ; 0,875\}}}=1
\end{aligned}
$$

\section{d. Normalisasi Matriks}

Merupakan hasil perhitungan alternatif yang dibuat ke dalam normalisasi matriks.

$$
\left[\begin{array}{cclccc}
1 & 1 & 0,286 & 0,875 & 1 \\
1 & 0,625 & 1 & 0,375 & 0,714 \\
0,6 & 0,375 & 0,333 & 1 & 1
\end{array}\right]
$$

\section{e. Menentukan perankingan}

Proses perangkingan merupakan proses perkalian normalisasi matriks dan bobot kriteria, perlu diketahui bobot kriteria untuk perhitungan ini adalah:

$w=(0,5570,2330,1130,0560,042)$
Selanjutnya melakukan perangkingan dengan formula berikut:

$$
\begin{aligned}
& \mathrm{v} 1=(0,557 * 1)+(0,233 * 1)+(0,113 * 0,286)+(0,056 * 0,7 \\
& 875)+(0,042 * 1)=0,913 \\
& \text { v2 }=(0,557 * 1)+(0,233 * 0,625)+(0,113 * 1)+(0,056 * 0,3 \\
& 75)+(0,042 * 0,714)=0,866 \\
& \text { v3 }=(0,557 * 0,6)+(0,233 * 0,375)+(0,113 * 0,333)+(0,0 \\
& 56 * 1)+(0,042 * 1)=0,557
\end{aligned}
$$

Langkah terakhir adalah penentuan ranking dengan mengurutkan jumlah $\mathrm{V}$ terbesar

Table 7. Perankingan alternatif

\begin{tabular}{lcr}
\hline Alternatif & $\begin{array}{c}\text { Nilai } \\
\text { prefensi } \\
\text { (Vi) }\end{array}$ & Ranking \\
\hline Indra A & 0,913 & 1 \\
\hline Reni A & 0,866 & 2 \\
\hline Supriyatna & 0,557 & 3 \\
\hline
\end{tabular}

Sumber : (Penelitian, 2019)

\section{KESIMPULAN}

Hasil dari penelitian yang telah dilakukan antara perhitungan menggunakan metode AHP dan SAW adalah adanya hasil yang sama yang didapatkan kedua metode tersebut, yaitu peringkat pertama diperoleh oleh Indra A, kedua oleh Renis A dan ranking terakhir adalah Supriyatna. Lalu untuk pererhitungan metode AHP menggunakan keseluruhan data dari sumber data sedangkan untuk metode SAW menggunakan perwakilan data saja dari sumber data dari responden. Juga perbedaan berikutnya terdapat pada pencarian nilai alternatif untuk Absensi yang menggunakan perhitungan alternatif Cost, yang berarti jika semakin kecil nilai Absensi guru, maka nilai bobot alternatif semakin baik. Kedua metode ini dapat dipergunakan untuk membantu keputusan kinerja guru terbaik dengan langkah-langkah yang berbeda antara metode tersebut, langkahp-langkah pada metode SAW lebih sedikit dibandingkan dengan AHP.

\section{REFERENSI}

Chintyari, Y. E., \& Priharin, T. (2015). Implementasi Metode Simple Additive Weighting untuk pemilihan Guru beprestasi pada SMP Islam Pondok Duta. Jurnal Ilmu Pengetahuan Dan Teknologi Komputer, 3(2), 81-89.

Duwiyanti, Fitri; Ardhiansyah, M. (2019). Sistem 
Pendukung Keputusan Pemilihan Guru Terbaik di SMK Pustek Serpong Dengan Menggunakan Metode TOPSIS. International Journal of Education, Science, Technology, and Engineering, 2(1), 45-67. https://doi.org/10.36079/lamintang.ijeste0201.18

Fauzi, A., \& Hidayatulloh, T. (2017). Penilaian Kinerja Karyawan Pada PT. Telecom Visitama Menggunakan Metode Analytical Hierarchy Process. Indonesian Journal on Computer and Information Technology, 2(2), 65-71.

Paramita, A., Mustika, F. A., \& Farkhatin, N. (2017). Aplikasi Sistem Pendukung Keputusan Guru Terbaik Berdasarkan Kinerja dengan Metode Analytical Hierarchy Process (AHP). Jurnal Nasional Teknologi Dan Sistem Informasi, $3(1), \quad 9-18$. https://doi.org/10.25077/teknosi.v3i1.2017.918

Pradipta, A. Y., \& Diana, A. (2017). Sistem Penunjang Keputusan Pemilihan Supplier pada Apotek dengan Metode AHP dan SAW (Studi Kasus Apotek XYZ). Sisfotek, 3584, 107-114.

Putra, A. S., Aryanti, D. R., \& Hartati, I. (2018). Metode SAW (Simple Additive Weighting) sebagai Sistem Pendukung Keputusan Guru Berprestasi ( Studi Kasus: SMK Global Surya). Prosiding Seminar Nasional Darmajaya, 1(1), 85-97. Retrieved from https://jurnal.darmajaya.ac.id/index.php/PSND /article/view/1233/763

Rahayu, W. (2017). Model Penentuan Guru Berprestasi Berbasis Adaptive Neuro Fuzzy Inference System ( Anfis ). 7(1), 101-107.

Satria, F., \& Mutiah. (2014). Sistem Pendukung Keputusan Penilaian Kinerja Guru Terbaik Pada Min Kedondong Menggunakan AHP (Analytic Hierarchy Process). Jurnal TAM ( Technology Acceptance Model ), 3(1), 21-31. https://doi.org/10.1007/s00531-005-0006-1

Shiddieq, D. F., \& Septyan, E. (2017). Penilaian Kinerja Karyawan ( Studi Kasus Di PT. Grafindo Media Pratama Bandung ). Lpkia, $1(1), 1-7$.

Suhada, S., Hidayatulloh, T., \& Fatimah, S. (2018). Penerapan Fuzzy MADM Model Weighted Product dalam Pengambilan Keputusan Kelayakan Penerimaan Kredit di BPR Nusamba Sukaraja ( The Application of Fuzzy MADM Model Weighted Product in Decisions Support of Credit Worthiness in the BPR Nusamba Sukaraja ). E-ISSN : 2579-9801, VI, 61-71. Retrieved from http://jurnalnasional.ump.ac.id/index.php/JUIT A/article/view/2517

Sunarti, S., \& Sundari, J. (2018). Perbandingan Metode SAW dan Profile Matching Pada Pemilihan Rumah Tinggal. Intensif, 2(2), 115. https://doi.org/10.29407/intensif.v2i2.12045 
